\title{
Ethics and Economics*
}

\section{Of Value and Values}

\section{Paul Dumouchel ${ }^{* *}$}

\section{Ethik und Ökonomik - Vom Wert und von Werten}

This paper argues that economics and ethics should not be seen as opposed and radically different, but rather as two versions or aspects of the same enterprise, that of providing rules of interactions for agents who are not attached by obligations of reciprocity. The particularity of modern economics - as opposed to traditional gift exchange - is not that it is without any ethical content but that it proposes an answer to the question: how should I behave towards those to whom I owe notbing. The only coherent answer to that question that is not imposed from the outside implies fairness as a selfregulating characteristic of exchange I argue. Values in the sense of value ethics are related to this enterprise as a way of resolving the problem that fairness in exchange and more generally reciprocity (once reciprocal obligations have disappeared) must presuppose itself and thus cannot be guaranteed.

Keywords: Ethics, Economics, Reciprocity, Obligations of Solidarity, Values, Ceremonial Gift

\section{Economics, ethics and values}

There exists a widespread tendency to see ethics and economics as two radically distinct domains; that is to say, not only as separate disciplines, but even as different world views whose preoccupations are foreign to each other. Some argue that this separation is a good thing. Ethical considerations according to them should be kept out of economics. Its scientific status requires independence from ethics and from all questions regarding values understood in the moral sense of the term. Its ability to guide us through economic difficulties and to lead us to affluence, demands a clearheaded, no non-sense, approach to economic issues. One where the hard decisions that can insure growth and fiscal health are not rendered impossible by moral 'sentimentalism'. As Keynes once said, "for at least another hundred years we must convince ourselves and others that what is good is bad and that what is bad is good, for what is bad is useful and what is good is not useful" (Keynes 1930/1972: 381). What would happen after one hundred years is not entirely clear. Even if nearly eighty years

The article has been subject to a double blind peer review process. Date of submission: 6th September, 2007; revisited version accepted for publication: 12th September, 2008.

** Prof. Paul Dumouchel, Core Ethics and Frontier Sciences, Ritsumeikan University, 56-1 Toji-in Kitamachi, Kita-ku, Kyoto 603-8577, Japan, phone: +81(0)-75-466-3325:, e-mail: dumouchp@ce. ritsumei.ac.jp, fields of expertise: philosophy, epistemology of social sciences, emotions, philosophy of biology.

I wish to thank Mark Anspach, Caroline Gerschlager, Reiko Gotoh, Marcel Hénaff and the two anonymous referees of $\mathbf{z f w \boldsymbol { u }}$ for very useful comments on previous versions of this text. 
have gone by since the great economist wrote that sentence, for many his claim is as valid today as it was then: what is wrong from a moral point of view can be good from an economic point of view and when such conflicts arise the authority of ethics should be overruled by the imperatives of economics.

Others argue to the contrary that the main problem is precisely the absence of ethics within economic thought and reflection. Our failure to take into account the ethical dimension of economic issues is what is essentially at stake. That is the reason why we should pursue and develop the dialogue between ethics and economics. What needs to be done is to work towards a kind of 'rapprochement' of ethics and economics that would allow us to take into consideration the ethical dimensions of economic questions and decisions. Others, finally, argue that the recommendations of good economic sense are not inconsistent with those of ethics. They are neither opposed nor foreign to the prescriptions of ethics. Rather, economics historically has been influenced by and reflects the universal values of autonomy, freedom, equity and equality that are central in our modern code of morality.

In the first two cases, we assume that economics and ethics constitute two distinct domains and the alternatives we are faced with are either to maintain this separation, which is viewed as a necessary condition of economic science, or to introduce (some) aspects of ethics into economics in order to make this last discipline more attentive to different dimensions of human existence which it tends to overlook. In the third case it is claimed that there is no fundamental separation between the two domains. The argument is that economics embodies a theory of ethics inasmuch as it includes a conception of justice and rests on values like freedom, autonomy, honesty, trust and hard work. ${ }^{1}$ Friedrich Hayek has even argued that what has made modern economies and complex societies possible are "rules of conduct" which are at odds with traditional morality (Hayek 1973). From this point of view, it is not so much economics that needs to learn from ethics than the other way around.

In this paper I propose an approach of the third type regarding the relations between ethics and economics. It stresses the continuity between the two domains, but also pays attention to the discontinuity that Hayek perceived. The first point I wish to defend is that ethics and economics should not be seen as entirely separate domains. Rather from its very beginning economics included an ethical dimension which, as many authors have argued, played a fundamental role in its success (e.g. Dumont 1977 as well as Hirschman 1977). There is an ethical element that is constitutive of modern economics and this is one of the things that distinguish it from traditional economics or more precisely that distinguish modern economic exchanges from the type of traditional exchange which they resemble most. Not only are ethics and economics not two separate domains, but they further constitute two instances of the same class of phenomena, two versions of the same project: attempts to provide rules of conduct for persons who are not attached to each other by reciprocal obligations. ${ }^{2}$ This is the

1 For a recent and radical version of this argument see McCloskey (2006).

2 Obligations are reciprocal in the following sense: when A's obligation towards B entails that B has in return an obligation towards A, such obligations are not contractual because agents do not 
second and central point I want to defend. The third is that the conflict between ethics and economics does not come from their supposed difference, for example from the opposition between self-interest on the one hand and universal impersonal values on the other. To the opposite, it stems from their similarity, from the fact that to a great extent both disciplines share the same goal: to organize and regulate interactions between agents who are not attached to each other by reciprocal obligations. Their rivalry comes from the fact that they compete for the same market.

This approach suggests that the relationship between ethics and economics should not be thought of in terms of values, for example as a conflict between different types of values or as the result of the fact that economics is a value free scientific discipline. Even if these ways of presenting the issue have been highly influential, there are, I believe, many reasons to be skeptical concerning both the existence of values and their usefulness as explanatory tools. It is certain that we value things, some more, some less, and that we attribute different values to different persons, objects, events and actions. It is even the case that there are some highly complex phenomena of valuation which suggest that more is at work here than a blind impenetrable preference. For example, Sen proposes to see values as second order preferences, preferences over preference orderings. ${ }^{3}$ However, it does not follow from all of this that there are such things as values: That is to say, the fact that we value certain things does not imply the existence of a particular category of intellectual objects that can be independently accessed by individuals and that motivate their action. Valuing something, either attributing a value to a person, action or event, or expressing second order preferences, is not the same as having a belief, for example the belief that some object $\mathrm{x}$ is better than another object $\mathrm{y}$. It is an action, not the contemplation of some intellectual content. In order to explain an individual's actions it is often useful to refer to his or her beliefs, but it does not require us to transform one, or a class, of those beliefs into a self-subsistent intellectual object named a value (Dumouchel 2005: 70-71). Furthermore, even if values exist, the explanation of peoples' behavior in terms of the values they have raises important methodological problems. The first one is that it is very difficult to draw a list of what constitutes, for example, Christian or European or humanist values. Depending on who they are agents will come up with (sometimes wildly) different sets of candidates for such values. A second, closely related problem is that it is even more difficult to know what any given value entails in terms of behavior or even beliefs. Some people who consider that life is a fundamental value are ready to blow up abortion clinics; others are pacifists for the same reason, and others again are vegetarians. These two difficulties suggest that values are not very promising tools to explain the behavior of agents. First because it is extremely difficult to know which values people "really" have. Did the nationalist theologians that eased the conscience of the young Argentinean officers who carried out the torture and murder of opponents during the 'dirty war' have Christian values or not? They certainly believed they did (Osiel et al. 2001: 104-148). Second because we do not know what

enter into them freely. They structure social intercourse between agents and constraint decisions of agents rather than being shaped by them.

3 What he sometimes refers to as "meta-rankings of preferences" (Sen 1982: 100-104). 
inferences concerning their behavior people draw from the values they have. This is a fundamental aspect of the difference between norms and values. Sociologists usually consider norms as social rules that are enforced either by specialists, as in the case of legal norms, or by an informal mechanism of social pressure as in the case of social conventions. To the contrary values are seen as intellectual objects that are transcendent in relation to any given social norm. In consequence the same value can be used both to ground a norm and to justify exceptions, depending from the very rule that it grounds. Unlike rules values do not provide any guidance as to how they should be applied. ${ }^{4}$ It follows that there is fundamental uncertainty concerning the way in which a value will be translated into behavior.

Faced with these difficulties it is possible to claim, for example, that people who blow up abortion clinics because they are pro-life do not understand the meaning of the value they pretend to be defending and draw from them the wrong inference concerning the actions these values should motivate. This is highly plausible, but if values are to help us to understand the actions of agents in the world it is not very helpful. Clearly it is not "values-as-they-should-be-understood" that motivate people to act, but 'values' as they are put to service by various agents, who many times will be 'wrong' or 'deviant' relative to what a social analyst considers is the proper impact the value in question should have on their action. In social science the question of knowing which actions are usually motivated by a particular value is an empirical question and it is not up to the whim, prejudice or even the best judgment of the analyst to decide what adopting a particular value entails (or should entail) in terms of an agent's behavior.

An alternative possibility is to define values like revealed preferences in economics. That is to say, values are used as short hand that groups into categories the objects that people value and that reflects the order of their preferences. Understood in this way, values lose some of their strangeness and ambiguity. Instead of being abstract objects in peoples' mind that guide them to act according to what an external observer declares to be their proper meaning, they simply are words that we use to describe what agents do. A person's values are revealed through his or her actions. This is a perfectly unobjectionable use of the term. However, it is important to note that values in this sense cannot explain why people value certain things. For if peoples' values are simply those things that people value then it is surely not because persons have certain values that they value the things they value! For this is equivalent to saying: "people value the things they value because they value the things they value"!

All these reasons suggest that we may be better off avoiding the concept of value as an explanatory tool. We may remain agnostic concerning the existence of values, but if it is true that the explanatory power of the concept of value is so limited, why do many people so often resort to it? The methodological difficulties that militate against the use of a concept of value also suggest a further question: why does this notion seem so evident to us? Whether or not values exist, in view of the previous discussion what needs to be explained is the success of the language of value and the fact that

4 See the special issue on „Exception, Excuses and Norm(e)s,” of the Canadian Journal of Law and Society (Dumouchel 2006). 
people refer to values to explain and justify some of their actions. It may be important to note that this has not always been the case. The word value is derived from 'valour' a term that traditionally was exclusively used in reference to 'military valour'. It is only in the first half of the $17^{\text {th }}$ century that value begins to acquire its modern sense, both economic and moral.

\section{Exchange modern and traditional}

Mark Anspach (2002: 58-68), in a brilliant comparative analysis of traditional gift exchange (ceremonial gift) and modern economic exchange, draws our attention to what he considers constitutes the fundamental characteristics of modern exchange. In a traditional society the exchange of goods, hospitality and gifts of all sorts serve as a way of establishing or of re-establishing and re-enforcing social bonds. That is to say, as Mauss (1980) pointed out in his famous essay on the gift, every gift creates an obligation and requires a counter-gift in return. The same applies to hospitality in ancient Greece for example. The gift of hospitality to a stranger creates a bond between the families of individuals from different cities, a bond that is so strong that in time of war, as we can read in Homer, it can justify that a man refuses to fight an enemy who is a member of his host family. The fact however that you sold a car to my brother not only does not create any obligation between you and me, it does not even entail any obligation on the part of my brother once the exchange has taken place, that is to say once the car has been paid. The central characteristic of modern exchange as compared to traditional exchange is that once it is concluded it leaves the agents as free as they were before. Modern exchange does not create any new obligation of reciprocity; it does not create any bond that attaches the agents to each other in a way that is different from what existed before the exchange. Once the transaction is over, that is it; it is over; nothing remains. The agents can turn their back on each other, go their own way; they do not owe anything to each other any more. Modern monetary exchange rather than creating a new obligation puts an end to the mutual obligations of the agents exchanging. There is no requirement of reciprocity, no obligation that extends beyond the transaction itself. Once it is over the agents are free to go their own way. In traditional exchange, however, a ceremonial gift either marks the beginning of a relation or it consolidates a relation. It creates a new obligation or reinforces an already existing obligation of reciprocity. The return gift unlike a payment in monetary exchange does not put an end to the relation; it does not liberate the agents from obligation but to the contrary makes the bond stronger. That is why in modern exchange, unlike what we find in traditional exchange, after having sold a car to my brother you are not in any way obligated to buy something from him or to sell him something else. Refusing to exchange does not threaten to trigger "negative reciprocity", the exchange of violence as it does in traditional societies. As Marcel Hénaff (2002) has shown, the role and function of ceremonial exchange is precisely to create and to strengthen the social bond, but obligations of solidarity - as we will see are not independent from duties of violence.

Some may wish to argue that similar phenomena often take place in the course of modern economic exchange. Repeated relations between enterprises are conducive to the appearance of something which is like an obligation, and that encourages trust, for 
example, between a small supplying enterprise and the larger manufacturer that for many years has been the exclusive buyer of all its production. Situations of this type are frequent and it can be argued that trust and 'obligations' in this sense are fundamental to the healthy functioning of economic exchanges. Furthermore, many authors in business ethics will argue that this trust should be honored even at the cost of some economic loss. However, nothing in economics requires it to be honored and prevents the buyer, in the previous example, from turning to a new supplier even if she knows that by doing so she condemns her previous business partner to bankruptcy. In reality, no reciprocal obligation exists here. Once a supplier has found a better market for his product or once a producer has found a supplier that offers more interesting terms, nothing prevents them from turning their back on their long term partner. More to the point, in modern economics no such obligation can exist. The freedom to change suppliers and to seek new buyers is fundamental to economic efficiency. Whether or not deserting a committed and reliable business associate for an immediate profit is wise or in the long term interest of an enterprise is a different issue. It is a question not of moral obligation but of rationality conceived as maximization. Situations, like the one sketched above are typically those where the addition of ethics to economics is seen as necessary.

However, what is at issue in the difference between traditional ceremonial exchange and modern economic exchange should not be viewed as an opposition between morality (traditional exchange) and immorality, or at least the absence of morality (modern exchange). ${ }^{5}$ What is at stake in the above example is not a deficit of morality that a supplement of ethics could cure. Rather we are dealing with different forms of morality and social contexts from which they are inseparable. Traditional exchange bears witness of a world divided between people towards whom an agent has specific obligations of solidarity and others towards whom he does not have any such obligations. What constitutes acceptable behavior towards persons belonging to the first group is quite different from what constitutes acceptable behavior towards individual members of the second group. These obligations are obligations of solidarity and of reciprocity in the sense that fulfilling one's obligation creates another obligation which the original recipient now has a duty to fulfill. Even when there is an important asymmetry, as is generally the case, between what is given and what is received, every gift creates an obligation and every obligation entails a counter obligation. According to the anthropologist Marshal Sahlins (1972), in primitive societies the type of exchange which resembles most what we view as economic exchange - exchanges where each partner tries to maximize his or her own advantage - are forbidden within the tribal space where obligations of solidarity reign. They can only take place in an intertribal space, which also constitutes the domain of warfare and negative reciprocity. Actually this is not entirely correct as we will soon see, but there is some truth in this claim as long as it is not understood as an indictment against modern economic exchange, as an underhanded way of suggesting that modern (capitalist) economic exchange is war under another name. What Sahlins's claim indicates, and it is fundamental, is that a central characteristic of modern economic exchange is that it takes

$5 \quad$ See for example the essays collected in Parry/Bloch (1989). 
place between agents who are not attached by reciprocal relations of solidarity. In modern terms, economic exchange relates free independent agents. It constitutes an instance of a rule of interaction between agents who are not bound by reciprocal obligation. In consequence, one of the many things that economic science which codifies and analyses exchange and economic activities in general does is to provide a set of rules of behavior for people who are not attached by reciprocal obligations. It gives answers to the question: how should I act towards people to whom I owe nothing? That is to say towards those who do not belong to my family, my clan, my tribe, those who speak a different language and wear strange clothes. Of course economic science does not perceive itself as doing this, but rather as resolving problems of production, distribution and allocation of scarce resources, which is certainly true. My claim is that exchange apart from its strictly economic functions also exemplifies a rule of behavior for agents who do not have reciprocal obligations of solidarity. Since exchange to a large extent is the root activity of modern economies, and is understood as such by economic science, this discipline also contains a set of rules and of recommendations about how agents who are not held by reciprocal obligations of solidarity should act towards each other.

How should I act towards those people with whom I do not have any obligation of reciprocity? What rules should coordinate our transactions? These are important questions. They also are new questions. In traditional societies, to those to whom you owe nothing, you owe nothing, that is to say, you do not have any obligation towards them. There are no rules of conduct which apply. You may do with them as you wish, or as you can. Exploit them, kill them, befriend them or introduce them into the domain of reciprocity and obligation through the magic of the gift or hospitality. Towards them and towards them alone you are free to act as you want. That is to say it is only in that domain that your actions toward others are not constrained by rules. In consequence the domain of relations with those towards whom one does not have any obligation of reciprocity is in traditional societies an uncharted, dangerous and chaotic domain. It is chaotic because there are no rules. It is dangerous because in that domain any relation can veer to violence. It is uncharted because it is dangerous and chaotic. In consequence it is a very small domain, one where few people will venture and then only rarely. The possibility of modern economic exchange rests on the taming of that domain while simultaneously maintaining its characteristic freedom. It must be pacified, regularities must emerge from interactions taking place within it so that agents can anticipate future events and be able to plan in consequence. This is what will allow this domain to grow. However, this taming or domesticating cannot be done by imposing obligations upon that domain similar to those that structure the existing space of reciprocity. If that were the case, the price to pay for making the domain hospitable would be to destroy it.

This is not an easy problem to solve. The difficulty is not simply to come up with rules of interaction with those towards whom one does not have any reciprocal relations. As we will see, there is a sense in which this is relatively easy to do. The difficulty is to invent rules that do not simply negate this domain. This difficulty is related to the fact that, contrary to what Sahlins suggests, negative reciprocity is not the opposite of solidarity but another aspect of it, its flip side, so to speak. Every obliga- 
tion of solidarity is simultaneously an obligation to avenge those with whom one is showing solidarity if they are attacked. Thus, there is no real opposition between positive and negative reciprocity. They are the heads and tails of the same coin. Obligations of solidarity impose duties of violence. Revenge is not the opposite of solidarity but continuous with it. This is why negative reciprocity is not reserved to intertribal space. It also exists within the realm of reciprocal relations of which it constitutes an important aspect.

Violence, negative reciprocity constitutes the simplest solution to the problem of dealing with those towards whom we have no reciprocal obligation. It does not pacify but certainly brings order into this uncharted and chaotic domain. Negative reciprocity allows regularities to arise and ensures that agents' anticipation concerning future events taking place in that domain will be satisfied. In a certain sense, what it does is to absorb the domain of interaction with those to whom we have no obligation of reciprocity into the periphery of the realm of reciprocal obligations, where these obligations are reduced to their simplest expression, that is, assured mutual violence. Negative reciprocity ensures that the domain of interaction with those to whom we have no reciprocal relation will remain small. It guarantees that this domain will never become richly populated with a wide variety of complex forms of relations.

The economic solution to the problem of providing rules of conduct with those to whom we are not linked by reciprocal obligations requires first of all to avoid or to escape negative reciprocity. Another way to say this is to argue that the sphere of interactions between agents who are not bound by obligations of reciprocity does not only need to be tamed, it first needs to be created and stabilized. Historically, there are many solutions to this problem and each one corresponds to the creation of a different type of domain of interaction with those to whom we have no obligation of solidarity. Slavery, conquest (ancient empires) and the law, among others, are different ways of institutionalizing the realm of interactions between agents who do not share obligations of reciprocity. In all those cases, the rules that apply to this domain come from outside of the domain. Interactions among those who do not have any reciprocal obligations are subjected to rules of conduct that are imposed from the outside by the conqueror or the state. These rules do not cover all the possible ways in which people who are not attached by reciprocal obligations can interact with each other. Mainly they guarantee that certain types of relations, especially negative reciprocity, are excluded.

Concerning these external rules, which at all times remain necessary for the existence of the domain, the particularity of modern economic activity is that it finds the rule of the relation in the relation itself. This is what Adam Smith discovered: "Whoever offers to another a bargain of any kind" he wrote "proposes to do this. Give me that which I want, and you shall have this which you want, is the meaning of every such offer; and it is in this manner that we obtain from one another the far greater part of those good offices which we stand in need of' (Smith 1975: 13). Barter, exchange, according to Smith, regulates itself. It is not subjected to any external rule. It flows from the agents' regard for their own self-interest and because of that it is by definition fair, given that no one would enter into such a transaction unless the condition is satisfied that what is to be received is at least worth what is to be given. Why is it fair? 
Economics teaches us that the deal is fair because it is self-regulating and that if it was not fair, it could not be self-regulating. The two characteristics are inseparable. Economic exchanges are only self-regulating to the extent that they are fair and they are only fair if they are self-regulating. That is to say they are only fair if they are exchanges in which free agents voluntarily enter.

Put differently, the rule is fair because no other rule is possible if the rule is to be taken from the relation itself. Deception, force or fraud cannot constitute such a rule. Neither a strategy that can be recursively applied if the agents are free to enter into the relation, in other words, if they do not have any reciprocal obligation of solidarity that attaches them to each other. You may, for example, once again lend money to a member of your family who regularly fails to reimburse you, but you will not do that for a stranger, for someone to whom you are only related through the interaction which consists in lending money. Fraud cannot be a rule in situations of independence and equality, but only an exception that excludes all prospects of further relation (Dumouchel 2005). Of course if traditional obligations bind you to a unique supplier or if she enjoys a de facto monopoly, unequal exchange, unfairness can become a rule, but not if agents are free to exit when they wish. Why must the rule be taken from the interaction itself? Why is exchange understood by Smith as a situation of independence and equality? The answer is: because he assumes that these interactions take place between individuals who are not attached by reciprocal obligations of solidarity.

\begin{abstract}
"But man has almost constant occasion for the help of his brethren, and it is in vain for him to expect it from their benevolence only. He will be more likely to prevail if he can interest their self-love in his favor, and show them that it is for their own advantage to do for him what he requires of them." (Smith 1975: 13)
\end{abstract}

Benevolence by definition is free. Some may wish to consider that we have a moral obligation and duty to be benevolent. In that sense, they will argue, it is not free. Viewed as a duty or a virtue, benevolence is nonetheless free because it is not reciprocal. If we have a duty to be benevolent towards others then this duty depends on them being benevolent towards us. It is a categorical obligation. That is to say it is a duty whose fulfillment neither requires nor brings forth a further obligation that unites the beneficiary to the benefactor. Otherwise, as Kant saw clearly, it is not benevolence, but an action done out of interest. Benevolence does not expect anything in return, if it does, it is not benevolence. Because of that benevolence is an obligation of a new and unheard kind. Unlike reciprocal obligations its scope is potentially unlimited. Considered as a categorical obligation, benevolence extends to all and is not limited to those toward whom we have reciprocal obligations. Benevolence can also be considered as a virtue. Like generosity, courage or honesty, benevolence so understood is a disposition towards certain behaviors that are considered desirable and commendable but to which we are not obliged as such, even though it is clear that there is a sense in which we ought to be courageous, benevolent or generous.

Duty or virtue, the point is generally taken that Smith recognizes that benevolence is unable to provide for our needs and this failure is precisely where the question of the relation of ethics to economics arises, the place where their conflict takes form. What can be the role of ethics in economics if self-interested exchange is what compensates for the failure of our virtues and duties? If it is because of the butcher's and the 
brewer's care for their interest, rather than because of their benevolence, that we should attend for our dinner, what place is left for ethics? However, even though it is true that Adam Smith recognizes the limits of benevolence, it is also the case that, unlike Sahlins, he takes its existence for granted. He presupposes that it is there and that it influences the behavior of the agents. It is not only an alternative that is reasonable enough for him to feel that he should mention it (and important enough for him to feel he should reject it), but if Smith recommends that we attend to the butcher's and the brewer's care for their own interest instead, it is because he also assumes that that care will not lead them to rob us or to sell us sub-standard products. That it will not push them to resort to force or fraud. Even when it is not strong enough to provide us with our dinner, benevolence is still present. As Daniel Finn (2006) argued, in order for the market to exist, agents must abstain from certain abusive behaviors in their relations with each other, precisely those which, according to Sahlins, in traditional societies are characteristic of exchanges between agents who are not bound by reciprocal obligations.

Benevolence understood in this (minimal) way is not a duty and not a virtue. Rather it is a "negative rule" in Hayek's sense. Minimal benevolence does not prescribe any specific action but it excludes some forms of behavior, e. g. resorting to negative reciprocity. Benevolence in the minimal sense is also a kind of "default rule" rather than a categorical imperative. It is the attitude with which one enters into a new relationship, but it can be abandoned if the other party proves to be ill disposed towards us. It is therefore a good disposition towards others that is conditional on their dispositions towards us, a kind of conditionally reciprocal disposition: I will be benevolent towards you to the extent, and as long as I can expect you to be benevolent towards me. Like the law reciprocal benevolence constitutes one of the necessary conditions for the existence of a self-regulating market of exchange. Though benevolence understood as a virtue or a duty we all have towards each other is insufficient to provide for the help we constantly need from each other, minimal benevolence is indispensable for the transformation of self-interest into public benefit. Without it, we would in vain look to the butcher's self-interest for our dinner, for we would be back in the Hobbesian state of nature.

\section{Value and values}

"People" writes John Rawls at the beginning of his Political Liberalism "are reasonable in one basic aspect when, among equals say, they are ready to propose principles and standards as fair terms of cooperation and to abide by them willingly, given the assurance that others will likewise do so" (Rawls 1993: 49). That is to say, among equals to be reasonable (at least in one basic aspect) means to act in a conditionally reciprocal way. It means, for example, to propose fair terms of cooperation and to abide by them as long as others are ready to do the same. Equals are those who have exactly the same obligations to one another. One way of ensuring that this condition will be satisfied is to arrange for people to only have obligations which they voluntarily contracted. That is to say, it implies ensuring that people who interact are free of all pre-existing obligations. In such conditions, agents who act fairly towards each other are reasonable and reasonable agents treat each other fairly. Fairness and reasonability 
presuppose each other inasmuch as for each person to be fair or reasonable, whether this is viewed as an attitude, a disposition, or a particular behavior, requires that the agent with whom she interacts "will likewise do so".

Exchange, according to Adam Smith, is self-regulating. When it takes place among agents who are unencumbered by pre-existing reciprocal obligations and free to exit the relation once the exchange has taken place, it is a relation where the rule of the relation can come from the relation itself, that is, a one shot convention that automatically polices itself. The reason why this is so, is because the goods exchanged constitute the salient point around which the agents coordinate their action. An exchange is fair if the agents voluntarily agree to the terms of the exchange which are nothing else than the goods exchanged. In that sense, value, exchange value, is the measure of goods fairly exchanged. The fairness and rationality of exchange is embodied in the reciprocal disposition of each agent to voluntarily exchange, that is to say, to hold his part of the deal, provided, of course, that the other will "likewise do so". If that condition is not satisfied, the agent can walk away, exit from the deal, or at least avoid any further interaction with the other. In this way he can limit his loss and perhaps even seek redress. What makes exchange self-regulating, in the sense that the rule that defines the interaction as fair comes from the interaction itself, is that once the exchange has taken place, it is in principle always immediately known whether or not the reciprocal condition is satisfied.

Of course to say that exchange is self-regulating does not mean that it is entirely or absolutely self-regulating. Like any self-regulating or self-organizing system of interaction it will only spontaneously arise in an environment where certain conditions are satisfied, for example where negative reciprocity is absent and where agents manifest minimal benevolence toward each other as well as reasonableness and fairness understood as conditionally reciprocal dispositions. The problem is that conditionally reciprocal dispositions understood as "fair terms of cooperation" must presuppose themselves. That is to say, each agent must consider that the other agent already harbors the disposition in order for him to adopt it. Because this is true of all, it makes sense to say that minimal benevolence or fairness or reasonableness presuppose themselves. Each of these dispositions can only exist and be socially efficient if it already exists and is efficient. However, unlike what happens in the case of exchange, there is no immediate test that allows one to decide whether or not the disposition is already present in the other agent. That is to say, considered as default rules of actions, conditionally reciprocal dispositions have no acid test because in order to play their social role as conditions of self-regulating exchange they must transcend any and every particular interaction.

No matter how reasonable it is to be benevolent or fair towards others if they are likewise disposed to do the same, this last condition, that which follows the if, is precisely what is difficult to satisfy. The reason why this is so, is not because others are perhaps unfair or unreasonable, to the contrary, it is because the disposition is conditionally reciprocal; that is to say, because it is the other's disposition to be fair or reasonable that makes it both fair and reasonable to be fair and reasonable. Values, I take it, are attempts to resolve this problem, both ethical values, like fairness or benevolence, and cultural values European values, Christian values, Western values, or 
national values. Ethical values can be seen as putting an end to the uncertainty which plagues those who have relinquished reciprocal obligations in favor of conditional reciprocity. They offer a way of cutting off the infinite regress that threatens conditional reciprocity. Construed as values, or as virtues or as categorical duties, benevolence, fairness, or reasonableness do not presuppose themselves. They exist independently of the actions or dispositions of others, as intellectual objects that can be grasped and acted upon. Because of that they can lead to desirable attitudes and dispositions independently of what others are expected to do. In this way values aim to compensate the absence of reciprocal obligation and constitute a way of motivating agents to act autonomously in a way that is desirable but that no one can require of them. However, as Adam Smith noted, in that role their success remains limited. More important is the fact that ethical values give rise to normative expectations, for example that people should be fair and benevolent. These expectations - unlike cognitive expectations - are typically relatively immune to counter examples. Even if many people are not fair or benevolent, we still believe that people should be fair and benevolent. Cultural values function as signs of mutual recognition independently of their particular content. While normative expectations reduce the uncertainty concerning the dispositions of other agents toward fair terms of cooperation, cultural values provide agents with signs enabling them to identify those who are supposedly similarly disposed. "Supposedly" because the problem is not to know whether agents are or are not really disposed to "likewise do so" but to jump start a disposition which presupposes itself.

Both ethics and economics aim at the same thing, to provide rules of interaction to agents who are not bound by reciprocal obligations. The main difficulty that such attempts face is that the only rules that can be stable and efficient in such circumstances are conditionally reciprocal rules of action. That is to say rules that presuppose themselves. 


\section{References}

Anspach M. R. (2002): A charge de revanche. Figures élémentaires de la réciprocité, Paris: Seuil. Dumont, L. (1977): Homo Aequalis, Paris: Gallimard.

Dumouchel, P. (2005): Rational Deception, in: Gerschlager, C. (Ed.): Deception in Markets, New York: Palgrave/Macmillan, 51-73.

Dumouchel, P. (2006) (Guest-Ed.): Exception, Excuses and Norm(e)s, Special Issue of the Canadian Journal of Law and Society, Vol. 21/No. 1.

Finn, D. K. (2006): The Moral Ecology of Markets, Cambridge: Cambridge University Press.

Hayek, von F. (1973): Law, Legislation and Liberty, Vol. 1: Rules and Order, Chicago: University of Chicago Press.

Hénaff, M. (2002): Le Prix de la Vérité. Le don, l'argent, la philosophie, Paris: Seuil.

Hirschman, A. O. (1977): The Passions and the Interests, Princeton: Princeton University Press.

Keynes, J. M. (1930/1972): Essays in Persuasion, Economic Possibilities for our GrandChildren, New York: MacMillan.

Mauss, M. (1980): Essai sur le don, forme et raison de l'échange dans les sociétés archaïques, in: Mauss, M. (Ed.): Sociologie et Anthropologie, Paris: PUF.

McCloskey, D. (2006): The Bourgeois Virtues: Ethics for a Capitalist Age, Chicago: University of Chicago Press.

Osiel, M. J./ Atrocity, M./ Evil, O./ Arendt, H. (2001): Criminal Consciousness in Argentina's Dirty War, New Haven: Yale University Press.

Parry, J./ Bloch M. (1989) (Eds.): Money and the Morality of Exchange, Cambridge: Cambridge University Press.

Rawls, J. (1993): Political Liberalism, New York: Columbia University Press.

Sablins, M. (1972): On the Sociology of Primitive Exchange, in: Sahlins, M. (Ed.): Stone Age Economics, Chicago: Aldine Publishing Company, 185-230.

Sen, A. K. (1982): Choice, Welfare and Measurement, Oxford: Basil Blackwell.

Smith, A. (1975): The Wealth of Nations, London: J.M. Dent \& Sons. 